\title{
Risk factors for failures of trabeculectomies performed without antimetabolites
}

\author{
Holger Mietz, Birgit Raschka, Günter K Krieglstein
}

\begin{abstract}
Aims-To assess the risk profile for the failure of trabeculectomies in a large group of patients who were selected to be operated on without the use of antimetabolites. This was done in an effort to find subgroups of patients who may not need antimetabolites for primary procedures.
\end{abstract}

Methods-Consecutive patients scheduled for routine trabeculectomies were operated during a 4 year period and were followed up for at least 6 months postoperatively. Patients were regularly examined in the glaucoma unit and by their local ophthalmologists. Pre- and postoperative data were evaluated and success rates determined.

Results-709 eyes of 566 patients were operated on; 534 eyes of 534 patients $(94.4 \%)$ were finally evaluated. The mean follow up was 27.9 (SD 13.6) months with a range of 6-62 months. Success rates for complete surgical success ranged from $59 \%$ in the best group with pigmentary dispersion syndrome to $0 \%$ in the worst group with neovascular glaucoma. Success rates of patients with POAG, pseudoexfoliation, chronic angle closure, pigmentary dispersion syndrome, and dysgenetic glaucoma were similar. Failure rates ranged from $11 \%$ in the best group (pseudoexfoliation) to $80 \%$ in the worst group (neovascular glaucoma). Failure rates were high in complicated forms of glaucoma such as traumatic $(30 \%)$, buphthalmus $(40 \%)$, and uveitic $(50 \%)$. For repeat trabeculectomies, the failure rate was $49 \%$ ( 20 of 41 eyes). The mean time until failure ranged from 2.7 months (traumatic) to 15.5 months (pigmentary dispersion syndrome) and was 4.9 months for repeat trabeculectomies.

Conclusion-Trabeculectomy performed in selected groups of patients has a favourable outcome without the use of antimetabolites. It may be possible to avoid antimetabolites in these groups of patients for primary procedures.

(Br F Ophthalmol 1999;83:814-821)

H Mietz

B Raschka

G K Krieglstein

Correspondence to: H Mietz, MD, Department of Ophthalmology,

University of Cologne, 50924

Koeln, Germany.

Accepted for publication 1 March 1999

Trabeculectomies performed according to the first description by Cairns ${ }^{12}$ or with slight modifications are the most frequently performed surgical procedure in lowering the intraocular pressure (IOP). Failures of trabeculectomies occur at a variable rate, and reports about long term success rates of this procedure are difficult to compare. At the present time, the advantage of the use of three different drugs to inhibit fibrosis at the episcleral level has been demonstrated in larger clinical studies. These drugs include steroids, 5-fluorouracil (5-FU) and mitomycin C (MMC). For the first two substances, data from 3 and 5 year follow up studies, respectively, with a prospective, randomised design are available. ${ }^{34}$ There are several clinical studies showing the efficacy and advantage of MMC for both complicated and uncomplicated forms of glaucoma. While many of the studies have no control group, ${ }^{5-10}$ some do. ${ }^{11} 12$

It may be accepted from clinical practice that the use of steroids has few side effects, so steroids should probably not be restricted to certain groups of patients. However, this may be the case for the antiproliferative agents 5-FU and MMC. An aspect from the most recent report of the 5-FU filtering study group ${ }^{4}$ is of interest. The use of 5-FU was recommended for the two subgroups which included pseudophakic glaucoma and repeat trabeculectomies. For these groups, the reported success rates were markedly lower than in all other studies reported..$^{13}$

Since there are only infrequent prospective studies available reporting the natural outcomes of trabeculectomies for uncomplicated cases of chronic open angle glaucoma, ${ }^{15-22}$ it is even more difficult to determine which cases have a higher risk for early or late failures than others. At a time where different treatments for enhancing the outcome of trabeculectomies are available, there is a need to obtain information on which risk factors are important and what risk of possible side effects can be tolerated.

Since the introduction of the routine use of MMC in our department, we followed prospectively the outcome of all trabeculectomies. Eyes with a higher risk for failure and eyes with secondary forms of glaucoma were operated on with MMC, while eyes with open angle glaucoma and when serious side effects of MMC were feared, were operated on without the use of MMC. We did not use 5-FU or Molteno implants. In this communication, we report the follow up on all cases where no MMC was used in order to determine the success rates of cases of uncomplicated and complicated glaucoma from a large group of patients.

\section{Materials and methods}

We evaluated the preoperative data, course, and outcome of all trabeculectomies per- 
Table 1 Study population

\begin{tabular}{ll}
\hline Characteristics & $n(\%)$ \\
\hline Number of eyes operated & $709(100.0)$ \\
Number of patients & $566(100.0)$ \\
$\quad$ charts not found & $17(3.1)$ \\
follow up less than 6 months & $15(2.7)$ \\
Remaining eyes & $670(94.3)$ \\
Remaining patients & $534(94.4)$ \\
Patients operated on both eyes & $136(24.0)$ \\
Eyes included in this study & 534 \\
Follow up of all 534 eyes & \\
$\quad$ mean (SEM) (months) & $27.9(0.60)$ \\
$\quad$ range (months) & $6-61$ \\
\hline
\end{tabular}

Table 2 Characteristics and diagnoses of patients

\begin{tabular}{|c|c|c|}
\hline Characteristics & & $\begin{array}{l}\text { No of eyes } \\
n(\%)\end{array}$ \\
\hline Number of eyes & & $534(100)$ \\
\hline Number of patients & & 534 \\
\hline \multicolumn{3}{|l|}{ Sex/age (years) } \\
\hline $\begin{array}{l}\text { Male (mean }(\mathrm{SD})) \\
\text { range }\end{array}$ & $\begin{array}{l}57.3(20.2) \\
2 \text { weeks- } 88 \text { years }\end{array}$ & \\
\hline $\begin{array}{l}\text { Female (mean }(\mathrm{SD})) \\
\text { range }\end{array}$ & $\begin{array}{l}62.2(18.5) \\
2 \text { weeks-91 years }\end{array}$ & \\
\hline \multicolumn{3}{|l|}{ Race } \\
\hline White & & $534(100)$ \\
\hline \multicolumn{3}{|l|}{ Sex } \\
\hline Female & & $258(48)$ \\
\hline Male & & $276(52)$ \\
\hline \multicolumn{3}{|l|}{ Type of glaucoma } \\
\hline primary open angle & & $209(39.1)$ \\
\hline pseudoexfoliation & & $117(21.9)$ \\
\hline $\begin{array}{l}\text { chronic angle closure } \\
\text { pigmentary dispersion }\end{array}$ & & $47(8.8)$ \\
\hline syndrome & & $34(6.4)$ \\
\hline buphthalmus & & $25(4.7)$ \\
\hline dysgenetic glaucoma & & $21(4.0)$ \\
\hline uveitic glaucoma & & $14(2.7)$ \\
\hline traumatic & & $10(1.9)$ \\
\hline neovascular glaucoma & & $5(0.9)$ \\
\hline steroid induced & & $3(0.5)$ \\
\hline malignant glaucoma & & $3(0.5)$ \\
\hline pseudophakic glaucoma & & $2(0.3)$ \\
\hline aniridia & & $2(0.3)$ \\
\hline Repeat trabeculectomy & & $41(7.9)$ \\
\hline
\end{tabular}

formed without MMC that were operated on by our department between January 1992 and December 1995. Informed consent was obtained from all patients before surgery. The location of all charts was monitored using a computerised system.

Patients were followed up by our glaucoma unit and/or their local ophthalmologists. Preoperative data included the type of glaucoma, the duration of the disease, the current and previous medications, current and previous intraocular pressure, visual acuity, and other ocular abnormalities. The computerised visual field tests (Humphrey field analyser, program
30-2) were obtained and repeated regularly. Patients were only eligible for the study when typical glaucomatous field defects were present. Intraocular pressures without medication were greater than $21 \mathrm{~mm} \mathrm{Hg}$ in all cases. No cases of low tension glaucoma were included.

The visual field examinations were not analysed statistically since some ophthalmologists use different programs. Cataract progression had an influence on the field tests, which makes it difficult to assess them objectively. The data from the visual field testing were used and were helpful in assessing the progression of glaucoma. Follow up information included current medications, visual acuity, intraocular pressure, ocular abnormalities, surgically related complications, and the need for further surgical procedures.

For statistical evaluation, we used the data of each patient from the last complete ocular examination performed either in our department or by their local ophthalmologist. To avoid bias, only the eye operated first was evaluated from patients where both eyes were operated with sufficient data available. This reduced the total number of eyes in the study considerably, but was done in an effort to improve the statistical power of the results.

The success rate was judged using frequently used definitions. ${ }^{34810}$ Complete success was defined as an IOP of less than or equal to 21 $\mathrm{mm} \mathrm{Hg}$ without antiglaucomatous medication; qualified success as an IOP of less than or equal to $21 \mathrm{~mm} \mathrm{Hg}$ with antiglaucomatous medication. For both groups, the visual field had to be stable except for increasing defects that were not related to glaucoma. In addition, the cup/disc ratio should not have any progression along the course of the follow up period.

Failures were defined as an IOP of greater than $21 \mathrm{~mm} \mathrm{Hg}$ under medication, progressive glaucomatous visual field loss combined with an increase of cupping of the optic disc regardless of the IOP, or the need for further antiglaucomatous surgical procedures.

In some patients, data from the Heidelberg retina tomograph (HRT, Heidelberg Engineering, Germany) were available and the information was thus used in monitoring the progression of the disease in concert with the above criteria.

For statistical analysis, the Wilcoxon log rank test was used in order to determine significant differences of visual acuities, IOP

Table 3 Data of the different groups operated

\begin{tabular}{llllll}
\hline Diagnosis & $\begin{array}{l}\text { Mean age at diagnosis } \\
\text { of glaucoma (years) }\end{array}$ & $\begin{array}{l}\text { Mean age at } \\
\text { surgery (years) }\end{array}$ & $\begin{array}{l}\text { Follow up } \\
\text { (months) }\end{array}$ & $\begin{array}{l}\text { Time until failure } \\
\text { (months) }\end{array}$ & $\begin{array}{l}\text { Rate of failure } \\
(\%)\end{array}$ \\
\hline Primary open angle & 57.9 & 65.7 & $28.7(0.9)$ & $13.0(2.4)$ & 15.0 \\
Pseudoexfoliation & 63.5 & 69.2 & $29.5(1.3)$ & $11.2(2.3)$ & 11.2 \\
Chronic angle closure & 56.2 & 63.6 & $29.3(2.0)$ & $8.7(4.9)$ & 12.8 \\
Pigmentary dispersion syndrome & 42.1 & 48.9 & $27.5(2.5)$ & $15.5(7.6)$ & 17.6 \\
Buphthalmus & 0.1 & 3.5 & $21.9(2.8)$ & $3.6(1.0)$ & 40.0 \\
Dysgenetic glaucoma & 39.6 & 43.1 & $24.9(2.5)$ & $10.6(3.1)$ & 23.8 \\
Uveitic glaucoma & 48.3 & 55.8 & $27.8(3.0)$ & $8.6(3.2)$ & 50.0 \\
Traumatic & 37.8 & 47.2 & $26.9(4.1)$ & $2.7(1.2)$ & 30.0 \\
Neovascular glaucoma & 62.3 & 64.6 & $31.0(6.8)$ & $12.5(6.4)$ & 80.0 \\
Repeat trabeculectomy & 32.0 & 47.2 & $24.7(2.5)$ & $4.9(1.2)$ & 48.8 \\
\hline
\end{tabular}

${ }^{\star}$ Mean (SEM) 
Table 4 Pre-and postoperative data of the different groups

\begin{tabular}{|c|c|c|c|c|c|c|c|c|c|}
\hline Diagnosis & $\begin{array}{l}\text { VA before } \\
\text { surgery }\end{array}$ & $\begin{array}{l}\text { VA last } \\
\text { visit }^{\star}\end{array}$ & $p$ Valuet & $\begin{array}{l}\text { IOP before surgery } \\
(\mathrm{mm} \mathrm{Hg}) \neq\end{array}$ & $\begin{array}{l}\text { IOP last visit } \\
(\mathrm{mm} \mathrm{Hg}) \ddagger\end{array}$ & $p$ Valuet & $\begin{array}{l}\text { Medications } \\
\text { before surgery } \neq\end{array}$ & $\begin{array}{l}\text { Medications } \\
\text { last visit } \neq\end{array}$ & $p$ Valuet \\
\hline Primary open angle & 0.48 & 0.38 & 0.0001 & $23.9(0.5)$ & $16.9(0.3)$ & 0.0001 & $2.5(0.07)$ & $0.8(0.07)$ & 0.0001 \\
\hline Pseudoexfoliation & 0.43 & 0.29 & 0.0001 & $26.5(0.9)$ & $16.2(0.5)$ & 0.0001 & $2.6(0.10)$ & $0.7(0.09)$ & 0.0001 \\
\hline Chronic angle closure & 0.48 & 0.34 & 0.0001 & $28.3(1.5)$ & $16.7(0.5)$ & 0.0001 & $2.4(0.14)$ & $0.7(0.14)$ & 0.0001 \\
\hline Pigmentary dispersion syndrome & 0.45 & 0.40 & 0.0001 & $29.1(2.0)$ & $15.8(0.7)$ & 0.0001 & $2.6(0.2)$ & $0.6(0.16)$ & 0.0001 \\
\hline Buphthalmus & 0.36 & 0.26 & 0.38 & $27.8(2.1)$ & $16.0(2.0)$ & 0.0001 & $0.6(0.21)$ & $0.2(0.14)$ & 0.20 \\
\hline Dysgenetic glaucoma & 0.69 & 0.61 & 0.42 & $25.8(1.7)$ & $17.9(1.7)$ & 0.007 & $2.3(0.14)$ & $1.0(0.26)$ & 0.0003 \\
\hline Uveitic glaucoma & 0.18 & 0.07 & 0.058 & $39.2(2.7)$ & $20.7(2.9)$ & 0.002 & $2.6(0.23)$ & $1.1(0.43)$ & 0.007 \\
\hline Traumatic & 0.14 & 0.10 & 0.069 & $32.3(4.5)$ & $17.8(1.0)$ & 0.008 & $2.3(0.40)$ & $1.0(0.42)$ & 0.009 \\
\hline Neovascular glaucoma & 0.07 & 0.03 & 0.78 & $31.8(3.6)$ & $21.4(4.2)$ & 0.089 & $3.2(0.20)$ & $1.6(0.40)$ & 0.007 \\
\hline Repeat trabeculectomy & 0.26 & 0.16 & 0.0001 & $29.0(1.4)$ & $18.8(0.9)$ & 0.0001 & $2.3(0.20)$ & $1.0(0.20)$ & 0.0001 \\
\hline
\end{tabular}

*Data given in decimals. They were transformed to $\log$ MAR data for calculation.

+Wilcoxon signed rank test.

$\ddagger$ Mean $(\mathrm{SEM})$.

All IOP values shown here were measured with medications.

Table 5 Success rates of the different groups

\begin{tabular}{|c|c|c|c|c|}
\hline \multirow[b]{2}{*}{ Diagnosis } & \multicolumn{2}{|l|}{ Success } & \multirow{2}{*}{$\begin{array}{l}\text { Combined } \\
\text { success rate } \\
\%(n)\end{array}$} & \multirow[b]{2}{*}{$\begin{array}{l}\text { Failure } \\
\%(n)\end{array}$} \\
\hline & $\begin{array}{l}\text { Complete* } \\
\%(n)\end{array}$ & $\begin{array}{l}\text { Qualifiedt } \\
\%(n)\end{array}$ & & \\
\hline Primary open angle & $53(112)$ & $32(66)$ & $85(178)$ & $15(31)$ \\
\hline Pseudoexfoliation & $51(60)$ & $38(44)$ & $89(104)$ & $11(13)$ \\
\hline Chronic angle closure & $53(25)$ & $34(16)$ & $87(41)$ & $13(6)$ \\
\hline Pigmentary dispersion syndrome & $59(20)$ & $23(8)$ & $82(28)$ & $18(6)$ \\
\hline Buphthalmus & $60(15)$ & $0(0)$ & $60(15)$ & $40(10)$ \\
\hline Dysgenetic glaucoma & $52(11)$ & $17(5)$ & $83(16)$ & $17(5)$ \\
\hline Uveitic glaucoma & $36(5)$ & $14(2)$ & $50(7)$ & $50(7)$ \\
\hline Traumatic & $50(5)$ & $20(2)$ & $70(7)$ & $30(3)$ \\
\hline Neovascular glaucoma & $0(0)$ & $20(1)$ & $20(1)$ & $80(4)$ \\
\hline Repeat trabeculectomy & $31(13)$ & $20(8)$ & $51(21)$ & $49(20)$ \\
\hline
\end{tabular}

Criteria used: ${ }^{\star} \mathrm{IOP}<22 \mathrm{~mm} \mathrm{Hg}$ and no medication; $\nmid \mathrm{IOP}<22 \mathrm{~mm} \mathrm{Hg}$ with medication; $\ddagger \mathrm{IOP}$ $>21 \mathrm{~mm} \mathrm{Hg}$ regardless of medication.

values, and the amount of medications between two examinations within the groups of patients. The Wilcoxon log rank test was also used in comparing different aspects between patients with a complete surgical success with those that failed. A statistically significant difference was assumed for $\mathrm{p}$ values lower than 0.05. Kaplan-Meier life table analysis was used to assess survival curves.

For further evaluation and statistical analysis (Tables 3, 4, 5) only such groups that included six or more eyes were evaluated. For the direct assessment of risk factors for failure, only eyes with POAG, pseudoexfoliation, and repeat trabeculectomies were evaluated (Tables 6, 7, 8 ), since these groups were large enough to obtain profound statistical data.

IOP was measured using Goldmann applanation tonometry. In cases with major corneal or axial and scleral abnormalities, such as buphthalmus, Perkins applanation tonometry was used. In each individual case, the same technique was applied in preoperative and follow up measurements. To determine the

number of medications used each topical medication was counted as one, if used according to the manufacturer's recommendation. Systemic treatment with carboanhydrase inhibitors counted as one point. Cases in which the maximum tolerable doses were used (three times $250 \mathrm{mg}$ ) counted as two points.

Visual acuities were taken using ETDRS charts and transformed into logMAR data for calculation and then retransformed into decimals. $^{23}$

\section{Results}

We examined a total of 709 cases from 566 patients who were operated on between January 1992 and December 1995. Of these 709 trabeculectomies, we were unable to locate information from $23(3.3 \%)$ eyes from 17 $(3.1 \%)$ patients (Table 1 ). All cases in which the follow up was less than 6 months were excluded from the evaluation. Cases with a follow up of less than 6 months included 16 $(2.3 \%)$ eyes from $15(2.8 \%)$ patients. Reasons for short follow up were: patients who failed to appear in the department or their local ophthalmologist and so could not be monitored $(n=10)$; patients who had emigrated $(n=3)$; or patients who died $(n=2)$. This left 670 eyes of 534 patients for evaluation.

A total of 276 men and 258 women were operated on. The mean age at the time of surgery of the men was 57.3 years and the mean age of the women was 62.2 years (Table 2). There was a statistical difference in the age distribution between these two groups ( $p<0.004$; unpaired $t$ test). The largest groups of patients had primary open angle glaucoma (POAG) $(39.1 \%)$ or pseudoexfoliation $(21.9 \%)$, while the other forms of complicated glaucoma were

Table 6 Success rates of eyes with primary open angle glaucoma (POAG)

\begin{tabular}{lllll}
\hline POAG (n=209) & Complete success $^{*}$ & Qualified success $^{*}$ & Failures $^{*}$ & Valuet $^{-}$ \\
\hline Age (years) & $64.5(1.0)$ & $67.2(1.2)$ & $66.6(1.8)$ & 0.31 \\
Sex & & & 56 & 0.64 \\
$\quad$ Female (\%) & 48 & 49 & 44 & 0.58 \\
$\quad$ Male (\%) & 52 & 51 & $2.7(0.2)$ & 0.84 \\
Amount of medications before surgery (n) & $2.6(0.1)$ & $2.7(0.1)$ & 75 & 0.84 \\
More than 3 years of topical treatment before surgery (\%) & 74 & 73 & $25.9(1.2)$ & 0.27 \\
IOP before surgery (mm Hg) & $24.4(0.7)$ & $22.4(0.7)$ & $7.3(1.0)$ & 0.56 \\
Duration of glaucoma before surgery (years) & $8.1(0.7)$ & $8.5(0.7)$ & 43 & 0.39 \\
Previous argon laser trabeculoplasty (\%) & 35 & 31 & 21 & 0.04 \\
Previous cataract surgery (\%) & 8 & 11 & 0 & 0.71 \\
Previous goniotomy & 1 & 1 & & \\
\hline
\end{tabular}

^Mean (SEM)

†Comparison between complete surgical success and failures, Wilcoxon rank test. 
Table 7 Success rates of eyes with pseudoexfoliation

\begin{tabular}{|c|c|c|c|c|}
\hline Pseudoexfoliation glaucoma $(n=117)$ & Complete success * & Qualified success* & Failures* & $p$ Valuet \\
\hline Age (years) & $68.4(0.9)$ & $70.9(1.1)$ & $68.5(1.8)$ & 0.17 \\
\hline \multicolumn{5}{|l|}{ Sex } \\
\hline Female (\%) & 46 & 56 & 50 & 0.78 \\
\hline Male (\%) & 54 & 44 & 50 & 0.83 \\
\hline Amount of medications before surgery (n) & $2.7(0.2)$ & $2.7(0.2)$ & $32.9(0.5)$ & 0.67 \\
\hline More than 3 years of topical treatment before surgery (\%) & 60 & 43 & 54 & 0.14 \\
\hline IOP before surgery $(\mathrm{mm} \mathrm{Hg})$ & $26.7(1.3)$ & $25.4(1.3)$ & $28.5(2.2)$ & 0.54 \\
\hline Duration of glaucoma before surgery (years) & $5.8(1.0)$ & $5.3(0.9)$ & $9.7(3.0)$ & 0.08 \\
\hline Previous argon laser trabeculoplasty $(\%)$ & 31 & 39 & 54 & 0.11 \\
\hline Previous cataract surgery $(\%)$ & 1.5 & 5 & 29 & 0.001 \\
\hline Previous goniotomy & 0 & 0 & 0 & 1.0 \\
\hline
\end{tabular}

$\star^{\star}$ Mean $(\mathrm{SEM})$

†Comparison between complete surgical success and failures, Wilcoxon rank test.

less frequent. In 48 cases $(7.9 \%)$, a repeat trabeculectomy was performed. Many of these patients had a diagnosis of buphthalmus (33\%).

The mean age of the patients at which the diagnosis of glaucoma was made was earliest in those with buphthalmus; in many of which the diagnosis was established at or soon after birth (Table 3). In patients with trauma and dysgenetic glaucoma, the diagnosis was established relatively early with a mean age of 37.8 and 39.6 years, respectively. Patients with POAG and pseudoexfoliation tended to be somewhat older with a mean age of 57.9 and 63.5 years, respectively. The mean interval between diagnosis and surgery was 7.8 years for the patients with POAG, 5.7 years for those with pseudoexfoliation, and 7.4 for patients with chronic angle closure. This interval was shorter in patients with buphthalmus (3.4 years). Newborns with the diagnosis of buphthalmus were usually operated on within a few weeks or months, but some individuals with buphthalmus were presented at a later stage of the disease. In patients with neovascular glaucoma, the interval was 2.3 years.

The mean follow up exceeded 20 months in all groups, with 31.0 months for eyes with neovascular glaucoma being the longest. The time until failure was short in eyes with trauma (mean 2.7 months), buphthalmus (mean 3.6 months), repeat trabeculectomy (mean 4.7 months), and longer in those with POAG (mean 13.3 months) and pigmentary dispersion syndrome (mean 15.5 months). The average time until failure of the trabeculectomy was not different among the four groups-POAG, pseudoexfoliation, chronic angle closure, pigmentary dispersion syndrome, and dysgenetic glaucoma $(\mathrm{p}<0.57$, unpaired $t$ test). The shortest interval was in eyes with traumatic glau- coma, followed by those with buphthalmus and repeat trabeculectomy (Table 3).

The mean visual acuity deteriorated in each of the different groups (Table 4). The deterioration was significant in eyes with POAG, pseudoexfoliation, chronic angle closure, pigmentary dispersion syndrome, and repeat trabeculectomies. The average IOP was lower following surgery in each group, and the amount of medication needed was also reduced. In eyes with buphthalmus, the amount of medications before surgery was low.

Success rates for complete surgical success and failures were largely different among the groups (Table 5). Success rates were similar for eyes with POAG, pseudoexfoliation, chronic angle closure, pigmentary dispersion syndrome, and dysgenetic glaucoma and ranged from $53 \%$ to $55 \%$. Failure rates were low and similar with a range from $11 \%$ to $17 \%$ for these groups. Failure rates were high for eyes with traumatic and uveitic glaucoma, buphthalmus, and neovascular glaucoma. For repeat trabeculectomies, the success rate was low with $31 \%$ and the rate for failures high with $48 \%$ (Fig 1).

When the large groups-POAG, pseudoexfoliation, and repeat trabeculectomy-were analysed individually, certain factors appeared to have a significant influence. In eyes with POAG (Table 6), only previous cataract surgery was a statistically significant risk factor between eyes that had a complete success and eyes with failure. The type of cataract surgery was an extracapsular procedure with a clear corneal incision without involvement of the conjunctiva. Other factors such as the amount of medications before surgery, the length of topical treatment before surgery, the duration of glaucoma before surgery, or previous argon

Table 8 Success rates of repeat trabeculectomy

\begin{tabular}{|c|c|c|c|c|}
\hline Repeat trabeculectomy $(n=41)$ & Complete success* & Qualified success & Failures* & $p$ Valuet \\
\hline Age (years) & $47.6(7.9)$ & $70.1(1.8)$ & $36.3(6.9)$ & 0.30 \\
\hline \multicolumn{5}{|l|}{ Sex } \\
\hline Female (\%) & 67 & 89 & 38 & 0.16 \\
\hline Male $(\%)$ & 33 & 11 & 62 & 0.003 \\
\hline Amount of medications before surgery (n) & $2.1(0.3)$ & $2.6(0.3)$ & $1.8(0.3)$ & 0.42 \\
\hline More than 3 years of topical treatment before surgery (\%) & 85 & 100 & 52 & 0.11 \\
\hline IOP before surgery $(\mathrm{mm} \mathrm{Hg})$ & $32.2(2.8)$ & $26.2(3.4)$ & $28.1(1.9)$ & 0.21 \\
\hline Duration of glaucoma before surgery (years) & $9.7(1.5)$ & $12.4(1.6)$ & $9.0(1.8)$ & 0.78 \\
\hline Previous argon laser trabeculoplasty $(\%)$ & 20 & 22 & 29 & 0.41 \\
\hline Previous cataract surgery $(\%)$ & 20 & 22 & 25 & 0.53 \\
\hline Previous goniotomy & 13 & 0 & 33 & 0.014 \\
\hline
\end{tabular}

$\star^{\star}$ Mean (SEM)

tComparison between complete surgical success and failures, Wilcoxon rank test. 

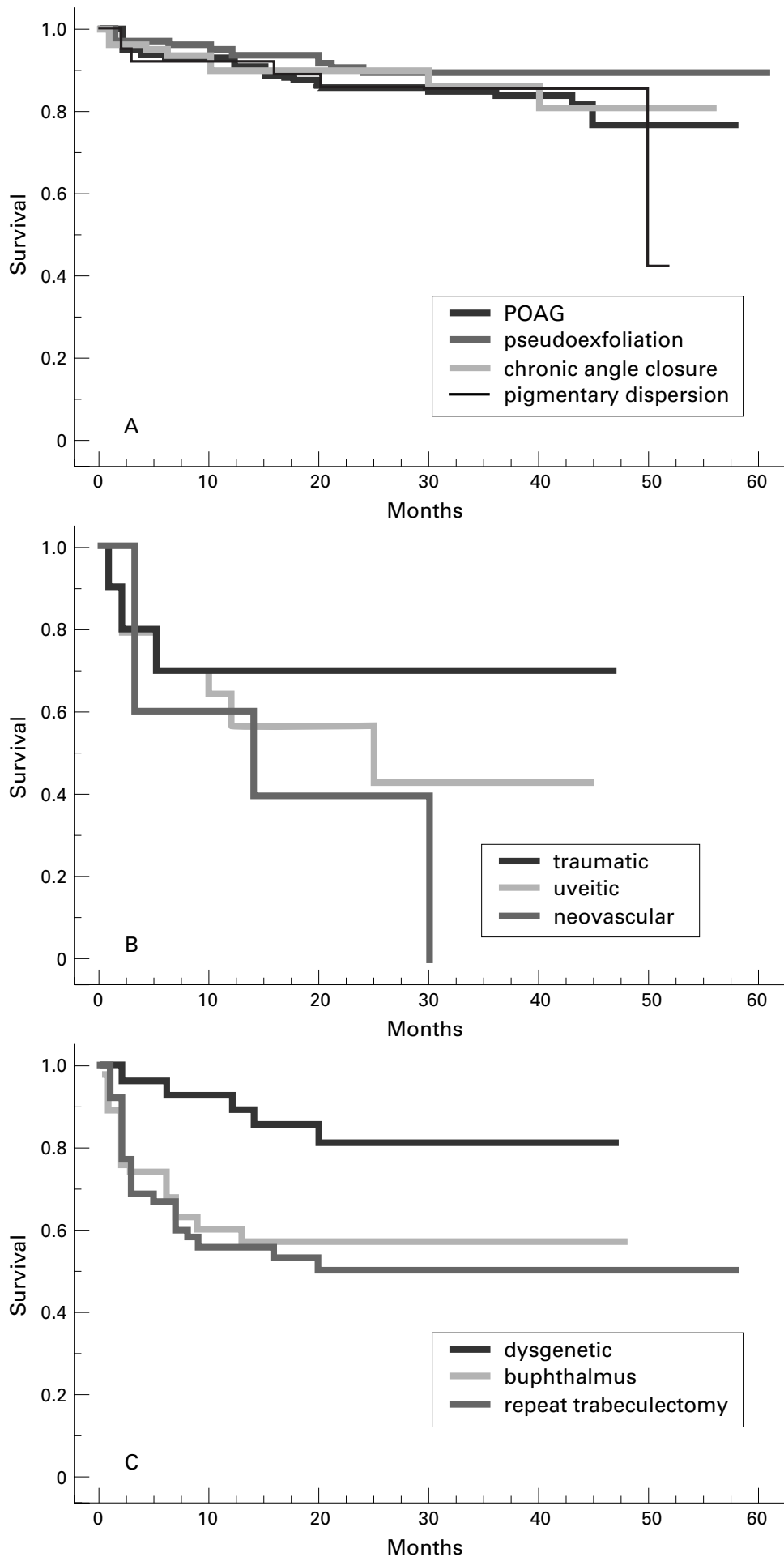

Figure 1 (A) Probability of surgical success in the subgroups with POAG, pseudoexfoliation, chronic angle closure, and pigmentary dispersion. The Kaplan-Meier survival plots showed no significant difference $(p=0.45, \log$ rank test). (B) Probability of surgical success in the subgroups with traumatic, uveitic, and neovascular glaucoma. The Kaplan-Meier survival plots showed no significant difference $(p=0.30, \log$ rank test). $(C)$ Probability of surgical success in the subgroups with dysgenetic glaucoma, buphthalmus, and repeat trabeculectomies. The Kaplan-Meier survival plots showed a significant difference $(p=0.017, \log$ rank test $)$. younger than their successful counterparts (Table 8), they were predominantly male, and had undergone previous goniotomy. This may be caused by the fact that this group includes a large number of eyes with buphthalmus. The rate of previous cataract surgery was not different among the groups.

\section{Discussion}

In this study, we have shown that the intermediate term results of trabeculectomies performed without the supplemental use of antimetabolites may have good results in selected cases. Variables that influenced the success rates included, mostly, the type of glaucoma. In subgroups the age, sex, and previous surgery such as goniotomy and cataract surgery were also important factors. The number of eyes in this report with sufficient follow up was relatively high at $94.3 \%$ This is considerably higher than in most clinical studies presented on this topic so far. The surgical skills of one or only a few surgeons had no large impact, since the procedures were performed by several different glaucoma surgeons during a 4 year period.

In previous years, intermediate term and long term results of trabeculectomies were relayed for both selected and unselected groups of patients at a time when few surgical alternatives such as the use of 5-fluorouracil and MMC, trans-scleral laser therapy, viscocanalostomy, or Molteno implants were available. ${ }^{15-17}{ }^{24-28}$ More recently, various studies focused on the issue of the use of MMC for primary procedures. ${ }^{5}{ }^{29}{ }^{30}$ In those reports the success rates for MMC operated eyes and controls varied widely. ${ }^{529}$ These results reflect the fact that patient selection is a crucial factor in clinical studies even when the studies are well executed.

The high success rate of trabeculectomies in patients with POAG has been repeatedly noted. Cairns ${ }^{2}$ in his early report in 1972 had a successful outcome in 78 of 80 eyes $(97.5 \%)$. D'Ermo et al ${ }^{24}$ found in a follow up study from 1 to 5 years a success rate of $71 \%$. In another retrospective long term follow up study, ${ }^{25}$ a success rate of $87 \%$ was reported in a total of 220 eyes with POAG and a follow up of up to 7 years. In a smaller study, Lewis and Phelps ${ }^{31}$ noted only a $65 \%$ success rate of trabeculectomies in eyes with POAG followed up for 5 years. Wilson ${ }^{32}$ reported a 7 year follow up study of 309 eyes with a success rate of $85 \%$. Inaba $^{33}$ studied the outcome of trabeculectomy in 427 eyes in the Japanese population and had an overall success rate of $75 \%$.

It has been repeatedly and most convincingly shown that antimetabolites are beneficial for cases with complicated forms of glaucoma. ${ }^{7934-36}$ However, the discussion at this time questions those cases that have fewer risk factors for the failure of trabeculectomy. Knowing about the sometimes deleterious side effects of the use of 5-FU or MMC, ${ }^{37-43}$ it may be necessary to re-evaluate risk factors in the failures of trabeculectomies and in describing groups of patients who have a low risk for the failure of primary procedures. On the other 
hand, it is also important to follow up patients with a presumed high risk for failure who were, for various reasons, operated on without antimetabolites in order to investigate their outcome.

The current study was possible because we used few therapeutic alternatives other than trabeculectomies during this time in our department. Trabeculectomies were performed either with or without MMC, and no 5-FU or Molteno implants were employed. It was therefore possible to study a large, heterogeneous group of patients who could avoid the use of MMC. Therefore, the results of this evaluation may serve to re-evaluate clinically important decisions.

Kupin et $a l^{29}$ studied the success of trabeculectomies performed with or without MMC in eyes with POAG. With a follow up of 12 months, the success rates were $85 \%$ for MMC operated eyes compared with $56 \%$ for the controls. It is unclear why the controls had such unfavourable results when compared with our patients with POAG who had a failure rate of only $16 \%$. Costa et al ${ }^{42}$ performed a similar study and again had a low success rate in POAG eyes that were operated without MMC with only $29 \%$ after a mean follow up of 16 months. Given the high success rates for trabeculectomy in such eyes in the present report, it is difficult to understand why the success rates were so different, and why MMC, which has a higher rate of complication, should be used in primary procedures in such cases.

Interestingly, in our study success rates were almost similar in eyes with POAG, pseudoexfoliation, and chronic angle closure. A similar result was found in a study in which success rates in younger individuals were evaluated. ${ }^{44}$ Risk factors with statistical significance in that investigation included previous cataract surgery, ALT, previous glaucoma surgery, and IOP larger than $40 \mathrm{~mm} \mathrm{Hg}$. Patients with dysgenetic glaucoma were significantly younger than those with POAG in our study, and success and failure rates were almost identical, so that we can support the finding from that study $^{44}$ that the age alone is not a general risk factor.

The best therapeutic approach for eyes with congenital glaucoma or buphthalmus is still controversial. While some authors report high success rates for trabeculotomy, ${ }^{16}{ }^{45}$ this procedure is not performed exclusively. At the current time, some glaucoma surgeons tend to favour trabeculectomies in those eyes as well. ${ }^{20}{ }^{46}{ }^{47}$ In general, treatment is difficult, and the average number of surgeries in controlling the IOP in this group is around three. ${ }^{48}{ }^{49}$ Success rates range from $35 \%$ in one study ${ }^{50}$ to $92 \% .{ }^{51}$ Because of the young age of the patients and its unknown long term side effects MMC is not yet generally acceptable in such cases. This was also the reason why our younger patients were operated on without MMC.

The results of the treatment of neovascular glaucoma with trabeculectomy again vary widely. In one report a success rate of $67 \%$ was described ${ }^{28}$ In a subgroup of the pilot study for $5-\mathrm{FU},{ }^{36}$ eyes were even operated on with the adjunctive use of 5-FU, and the 5 year success rate was only $28 \%$. In that report, the median survival time was 39 months. In our study, the mean time until failure was 12.5 months with a high failure rate of $80 \%$. It may be appropriate to use MMC primarily in those cases to improve the success rate of the first surgical intervention.

Uveitic glaucoma is a secondary form of glaucoma, which is usually associated with a poor prognosis for filtering procedures. It may be that certain factors within the aqueous humour in those eyes influence or accelerate the wound healing response at the subconjunctival and episcleral level. ${ }^{52}$ Both Patitsas et al ${ }^{35}$ and Jampel et $a l^{53}$ operated on eyes with uveitic glaucoma with the aid of 5-FU. In the first study, $71 \%$ of the eyes were controlled after a mean follow up of 34 months, while in the latter the IOP was controlled in all 12 eyes. The mean 5-FU dosage was $58 \mathrm{mg}$ and $33 \mathrm{mg}$, respectively. Prata et $a l^{34}$ used MMC with a concentration of $0.2 \mathrm{mg} / \mathrm{ml}$ and $0.5 \mathrm{mg} / \mathrm{ml}$. From 24 cases operated $18 \quad(75 \%)$ were controlled after a mean follow up of 9.8 months. All failures were operated with the lower concentration of $0.2 \mathrm{mg} / \mathrm{ml}$. In our study, a complete surgical success was only achieved in $36 \%$ of the cases, while the mean follow up was 28 months. It seems that the supplementation of trabeculectomies with antimetabolites serves to obtain markedly better results in this group of patients.

Eyes with one failed filtering procedure are obviously at high risk for consecutive similar surgical procedures. It is interesting that in the well executed, long term follow up 5-FU study ${ }^{4}$ it was stated that caution should be exercised in the use of 5-FU in cases that usually have a good prognosis. In contrast with that report, Goldenfeld et $a l^{54}$ used 5-FU in primary procedures on patients with POAG. The average follow up time was 20 months, and the success rate of the $5-\mathrm{FU}$ operated eyes was $94 \%$ compared with $73 \%$ in the controls. Success was defined as an IOP of less than $21 \mathrm{~mm}$ $\mathrm{Hg}$ regardless of the need of antiglaucomatous medication.

The influence of chronic topical antiglaucomatous therapy on the outcome of filtering surgical procedures has long been noted. Lamping $e t a l^{55}$ retrospectively studied the outcome of 252 eyes with either full thickness procedures or trabeculectomies that had undergone surgery without previous topical therapy. The 4 year success rate for trabeculectomies was $76 \%$, not much different from our patients with previous topical therapy. Johnson et $a l^{56}$ studied a total of 150 eyes that had or not had a history of long term medical therapy with $\beta$ blockers and found no difference in the success rates between eyes of the two different groups. Broadway et $a l^{57}$ performed a similar study and revealed that the use of $\beta$ blockers before surgery did not change the outcome significantly. However, the additional use of miotics and/or sympathomimetics did reduce the success rates. The increasing number of previous topical medications was associated with an increase of pale cells, macrophages, and 
lymphocytes in the superficial conjunctival layers. In the current study, we were unable to reveal a significant difference in topically applied medications when we compared the two groups with complete success and failures.

The influence of ALT on the success of trabeculectomies has been discussed in the past. Spaeth and Baetz ${ }^{58}$ found in a large, prospective study that ALT controls the IOP in 33\% of the cases for 5 years. Johnson et al ${ }^{56}$ showed that eyes with a history of previous ALT had a lower success rate following trabeculectomy after 1 year with $75 \%$ versus $91 \%$. In our study, we did not find that those eyes with previous ALT were significantly more often associated with failures (Table 7).

In summary, we have shown that in the era where powerful antifibrotic agents are available for immediate use to the glaucoma surgeon, it is worthwhile analysing the risk profile of each case in order to determine whether their use may be beneficial or necessary. In selected groups of patients with POAG, pseudoexfoliation, chronic angle closure, and dysgenetic glaucoma, success rates are encouragingly high without the use of any additional substances. Success rates were well below $50 \%$ in other groups of secondary glaucoma such as repeat trabeculectomies, uveitic, traumatic, and neovascular glaucoma, so that the initial use of adjunctive medication may be the correct choice.

1 Cairns JE. Trabeculectomy: preliminary report of a new method. Am $\mathcal{f}$ Ophthalmol 1968:673-9.

2 Cairns JE. Surgical treatment of primary open angle glaucoma. Trans Ophthalmol Soc UK 1972;92:745-56.

3 Araujo SV, Spaeth GL, Roth SM, et al. A ten-year follow-up on a prospective, randomized trial of postoperative corticosteroids after trabeculectomy. Ophthalmology 1995;102: 1753-9.

4 The Fluorouracil Filtering Surgery Study Group. Five-year follow-up of the fluorouracil filtering surgery study. $A \mathrm{~m} \mathcal{F}$ follow-up of the fluorouracil

5 Costa VP, Moster MR, Wilson RP, et al. Effects of topical mitomycin C on primary trabeculectomies and combined mitomycin C on primary trabeculectomies
procedures. Br f Ophthalmol 1993;77:693-7.

6 Ramakrishnan R, Michon J, Robin AL, et al. Safety and efficacy of mitomycin $\mathrm{C}$ trabeculectomy in southern India Ophthalmology 1993;100:1619-23

7 Chen CW, Huang HT, Bair JS, et al. Trabeculectomy with simultaneous topical application of mitomycin-C in refractory glaucoma. $\mathcal{F}$ Ocular Pharmacol 1990;6:175-81

8 Kitazawa Y, Kawase $\mathrm{K}$, Matsushita $\mathrm{H}$, et al. Trabeculectomy with mitomycin. A comparative study with fluorouracil. Arch Ophthalmol 1991;109:1693-8.

9 Palmer SS. Mitomycin as adjunct chemotherapy with trabeculectomy. Ophthalmology 1991;98:317-21.

10 Skuta GL, Beeson CC, Higginbotham EJ, et al. Intraoperative mitomycin versus postoperative 5-fluorouracil in highrisk glaucoma filtering surgery. Ophthalmology 1992;99: 438-44.

11 Wallace DK, Plager DA, Snyder SK, et al. Surgical results of secondary glaucomas in childhood. Ophthalmology 1998; 105:101-11.

12 Kim YY, Sexton RM, Shin DH, et al. Outcomes of primary phakic trabeculectomies without versus with $0.5-$ to 1 -minute versus 3 - to 5-minute mitomycin c. $A m$ f Ophthalmol 1998;126:755-62.

13 Smith MF, Sherwood MB, Doyle WD, et al. Results of intraoperative 5-fluorouracil supplementation on trabeculectomy for open-angle glaucoma. Am $\mathcal{f}$ Ophthalmol 1992;114:737-41.

14 Feldman RM, Dietze PJ, Gross RL, et al. Intraoperative 5-fluorouracil administration in trabeculectomy. f Glaucoma 1994;3:302-7.

15 Yamashita H, Eguchi S, Yamamoto T, et al. Trabeculectomy: a prospective study of complications and results of long-term follow-up. Fpn f Ophthalmol 1985;29:250-62.

16 Luntz MH, Livingston DG. Trabeculotomy ab externo and trabeculectomy in congenital and adult-onset glaucoma. Am f Ophthalmol 1977;83:174-9.

17 Jerndal T, Lundström M. 330 Trabeculectomies. A long time study (3-51/2 years). Acta Ophthalmol 1980;58:94756.
18 Nouri-Mahdavi K, Brigatti L, Weitzman M, et al. Outcomes of trabeculectomy for primary open-angle glaucoma. Ophthalmology 1995;102:1760-9.

19 Chen TC, Wilensky JT, Viana MA. Long-term follow-up of initially successful trabeculectomy. Ophthalmology 1997; 104:1120-5.

20 Dureau P, Dollfus H, Cassegrain C, et al. Long-term results of trabeculectomy for congenital glaucoma. $\mathcal{F}$ Pediatr Ophthalmol Strabismus 1998;35:198-202.

21 Jay JL, Allan D. The benefit of early trabeculectomy versus conventional management in primary open angle glaucoma relative to severity of disease. Eye 1989;3:528-35.

22 Migdal C, Gregory W, Hitchings R. Long-term funtional outcome after early surgery compared with laser and medicine in open-angle glaucoma. Ophthalmology 1994;101: $1651-6$

23 Westheimer G. Scaling of visual acuity measurements. Arch Ophthalmol 1979;97:327-330.

24 D'Ermo F, Bonomi L, Doro D. A critical analysis of the long-term results of trabeculectomy. Am $\mathcal{f}$ Ophthalmol 1979;88:829-35.

25 Mills KB. Trabeculectomy; a retrospective long-term follow-up of 444 cases. Br f Ophthalmol 1981;65:790-5.

26 Gross RL, Feldman RM, Spaeth GL, et al. Surgical therapy of chronic glaucoma in aphakia and pseudophakia. Ophthalmology 1988;95:1195-201.

27 Heuer DK, Gressel MG, Parrish II RK, et al. Trabeculectomy in aphakic eyes. Ophthalmology 1984;91:1045-51.

28 Allen RC, Bellows R, Hutchinson BT, et al. Filtration surgery in the treatment of neovascular glaucoma. Ophthalmology 1982;89:1181-7.

29 Kupin TH, Juzych MS, Shin DH, et al. Adjunctive mitomycin c in primary trabeculectomy in phakic eyes. $\mathrm{Am} \mathcal{F} \mathrm{Oph}-$ thalmol 1995;119:30-9.

30 Kitazawa Y, Suemori-Matsushita H, Yamamoto $\mathrm{T}$, et al. Low-dose and high-dose mitomycin trabeculectomy as an initial surgery in primary open-angle glaucoma. Ophthalmology 1993;100:1624-8.

31 Lewis RA, Phelps CD. Trabeculectomy v thermosclerostomy. A five-year follow-up. Arch Ophthalmol 1984;102: 533-6.

32 Wilson P. Trabeculectomy: long-term follow-up. $\mathrm{Br} f$ Ophthalmol 1977;61:535-8.

33 Inaba $Z$. Long-term results of trabeculectomy in the Japanese: an analysis by life-table method. fpn f Ophthalmol 1982;26:361-73.

34 Prata JA, Neves RA, Minckler DS, et al. Trabeculectomy with mitomycin $\mathrm{C}$ in glaucoma associated with uveitis. Ophthalmic Surg 1994;25:616-20.

35 Patitsas CJ, Rockwood EJ, Meisler DM, et al. Glaucoma filtering surgery with postoperative 5-fluorouracil in patients with intraocular inflammatory disease. Ophthalmology 1992;99:594-9

36 Tsai JC, Feuer WJ, Parrish II RK, et al. 5-Fluorouracil filtering surgery and neovascular glaucoma. Ophthalmology 1995;102:887-93.

37 Rubinfeld RS, Pfister RR, Stein RM, et al. Serious complications of topical mitomycin-C after pterygium surgery. Ophthalmology 1992;99:1647-54

38 Yamanouchi U. Scleral changes induced by instillation of mitomycin C. Acta Med Nagasaki 1983;28:99-110.

39 Costa VP, Wilson RP, Moster MR, et al. Hypotony maculopathy following the use of topical mitomycin C in glaucoma filtration surgery. Ophthalmic Surg 1993;24:389-

40 Jampel HD, Pasquale LR, Dibernardo C. Hypotony macuopathy following trabeculectomy with mitomycin C. Arch Ophthalmol 1992;110:1049-50.

41 Shields MB, Scroggs MW, Sloop CM, et al. Clinical and histopathologic observations concerning hypotony after trabeculectomy with adjunctive mitomycin C. Am f Ophthalmol 1993;116:673-83.

42 Costa VP, Comegno PEC, Vasconcelos JPC, et al. Low-dose mitomycin $\mathrm{C}$ trabeculectomy in patients with advanced glaucoma. F Glaucoma 1996;5:193-9.

43 Mietz H, Addicks K, Diestelhorst M, et al. Extraocular application of mitomycin C in a rabbit model: cytotoxic effects on the ciliary body and epithelium. Ophthalmic Surg $1994 ; 25: 240-4$

44 Stürmer J, Broadway DC, Hitchings RA. Young patient trabeculectomy. Assessment of risk factors for failure. $O p h-$ thalmology 1993;100:928-39.

45 McPherson SD, McFarland D. External trabeculotomy for developmental glaucoma. Ophthalmology 1980;87:302-5.

46 Agarwal HC, Sood NN, Sihota R, et al. Mitomycin-c in congenital glaucoma. Ophthalmic Surg Lasers 1997;28:979-85.

47 Beck AD, Wilson WR, Lynch MG, et al. Trabeculectomy with adjunctive mitomycin $\mathrm{c}$ in pediatric glaucoma. $A m \mathcal{F}$ Ophthalmol 1998;126:648-57.

48 Shaffer RN. Prognosis of goniotomy in primary infantile glaucoma. Trans Am Ophthalmol Soc 1982;80:321.

49 Leydhecker W. Glaukom. Ein Handbuch. Heidelberg: Springer-Verlag, 1973:69.

50 Gressel MG, Heuer DK, Parrish RK. Trabeculectomy in young patients. Ophthalmology 1984;91:1242-6.

51 Fulcher T, Chan J, Lanigan B, et al. Long-term follow up of primary trabeculectomy for infantile glaucoma. $\mathrm{Br} f$ Ophthalmol 1996;80:499-502.

52 Herschler J, Chaflin AJ, Fiorentino G. The effect of aqueous humor on the growth of subconjunctival fibroblasts in tissue culture and its implication for glaucoma surgery. $\mathrm{Am}$ f Ophthalmol 1980;89:245-9. 
53 Jampel HD, Jabs DA, Quigley HA. Trabeculectomy with 5 -fluorouracil for adult inflammatory glaucoma. Am $\mathcal{f}$ Ophthalmol 1990;109:168-73.

54 Goldenfeld $M$, Krupin $\mathrm{T}$, Ruderman JM, et al. 5-Fluorouracil in initial trabeculectomy. Ophthalmology 1994;101:1024-9.

55 Lamping KA, Bellows AR, Hutchinson BT, et al. Long-term evaluation of initial filtration surgery. Ophthalmology 1986 93:91-101.
56 Johnson DH, Yoshikawa $\mathrm{K}$, Brubaker RF, et al. The effect of long-term medical therapy on the outcome of filtration long-term medical therapy on the outcom
surgery. Am $\mathcal{F}$ Ophthalmol $1994 ; 117: 139-48$.

57 Broadway DC, Grierson I, O'Brien C, et al. Adverse effects Broadway DC, Grierson I, O'Brien C, et al. Adverse effects
of topical antiglaucoma medication. II. The outcome of filtration surgery. Arch Ophthalmol 1994;112:1446-54.

58 Spaeth GL, Baetz KA. Argon laser trabeculoplasty controls one third of cases of progressive, uncontrolled, open angle glaucoma for 5 years. Arch Ophthalmol 1992;110:491-4. 